DOI: $10.15593 / 2224-9982 / 2020.60 .06$

УДК 519.9: 629.7

\author{
М.Ю. Егоров ${ }^{1}$, В.О. Городнев ${ }^{2}$, Д.М. Егоров ${ }^{2}$, С.М. Егоров ${ }^{2}$ \\ ${ }^{1}$ Пермский национальный исследовательский политехнический университет, Пермь, Россия \\ ${ }^{2} \mathrm{AO}$ «Научно-исследовательский институт полимерных материалов», Пермь, Россия \\ ЧИСЛЕННОЕ ИССЛЕДОВАНИЕ ДИНАМИКИ ВНУТРИКАМЕРНЫХ \\ ПРОЦЕССОВ В РАКЕТНОМ ДВИГАТЕЛЕ ДЛЯ МОБИЛЬНЫХ \\ КОМПЛЕКСОВ С МНОГОШАШЕЧНЫМ ПОРОХОВЫМ ЗАРЯДОМ
}

\begin{abstract}
Ракетный двигатель на твердом топливе - сложная техническая система, в которой одновременно протекает ряд взаимосвязанных нестационарных и существенно нелинейных физико-химических процессов. Рассматриваемый тип РДТТ имеет свою проблематику и свои конструктивные особенности. Для оптимизации параметров ракетного двигателя исследуется динамика его внутрикамерных процессов. Метод исследования - постановка вычислительного эксперимента. Рассматривается сопряженная постановка задачи, включающая в себя: срабатывание воспламенительного устройства; прогрев, воспламенение и последующее нестационарное и турбулентное горение порохового заряда; нестационарное трехмерное ударно-волновое и вихревое гомогенно-гетерогенное течение воздуха и продуктов сгорания в камере сгорания, сопловом блоке и за сопловым блоком; разгерметизацию камеры сгорания и последующий вылет заглушки соплового блока. Каждая из подзадач рассматривается во взаимосвязи и разрешается одновременно - на одном шаге по времени. В результате исследований установлено, что при срабатывании РДТТ в его камере сгорания реализуется аномальный процесс, связанный с сегрегацией режима горения многошашечного порохового заряда. Приводятся результаты численных расчетов, на основании которых разработаны мероприятия конструктивного характера для исключения этого нежелательного эффректа.

Ключевые слова: численное исследование, ракетный двигатель на твердом топливе, внутрикамерные процессы, аномальный режим горения.
\end{abstract}

\author{
M.Yu. Egorov1, V.O. Gorodnev², D.M. Egorov², S.M. Egorov² \\ ${ }^{1}$ Perm National Research Polytechnic University, Perm, Russian Federation \\ ${ }^{2}$ JSC " Scientific-Research Institute of Polymer Materials", Perm, Russian Federation
}

\title{
NUMERICAL STUDY OF THE DYNAMICS OF INTRA-CHAMBER PROCESSES IN A ROCKET ENGINE FOR MOBILE COMPLEXES WITH A MULTI-TURRET POWDER CHARGE
}

\begin{abstract}
A solid-fuel rocket engine is a complex technical system in which a number of interrelated non - stationary and substantially nonlinear physical and chemical processes simultaneously occur. The type of SFRE under consideration has its own problems and design features. To optimize the parameters of a rocket engine, we study the dynamics of its internal processes. The research method is to set up a computational experiment. We consider the conjugate statement of the problem, which includes: triggering of the ignition device; - heating, ignition and subsequent unsteady and turbulent combustion of the powder charge; - unsteady threedimensional shock wave and a vortex of homogeneous-heterogeneous flow of air and products of combustion in the combustion chamber, nozzle block and launchers unit; - depressurization of the combustion chamber and the subsequent departure of the stub nozzle block. Each of the subtasks is considered in a relationship and resolved simultaneously - at a single time step. As a result of researches it is established that when triggered, the solid-propellant in the combustion chamber is implemented by an abnormal process associated with the segregation of the combustion mode of multi-turret powder charge. The results of numerical calculations are presented, on the basis of which constructive measures are developed to eliminate this undesirable effect.
\end{abstract}

Keywords: numerical study, the rocket engine solid fuel, the in-cell processes, abnormal mode of burning.

Ракетный двигатель на твердом топливе (РДТТ) - сложная техническая система, в которой одновременно протекает ряд взаимосвязанных (сопряженных) нестационарных и существенно нелинейных физико-химических процессов [1-14 и др.]. Рассматриваемый РДТТ для мобильных комплексов с многошашечным пороховым зарядом высококалорийного модифицированного баллиститного твердого топлива в виде набора полых цилиндрических трубок имеет свою проблематику и свои конструктивные особенности. Типовой вариант 


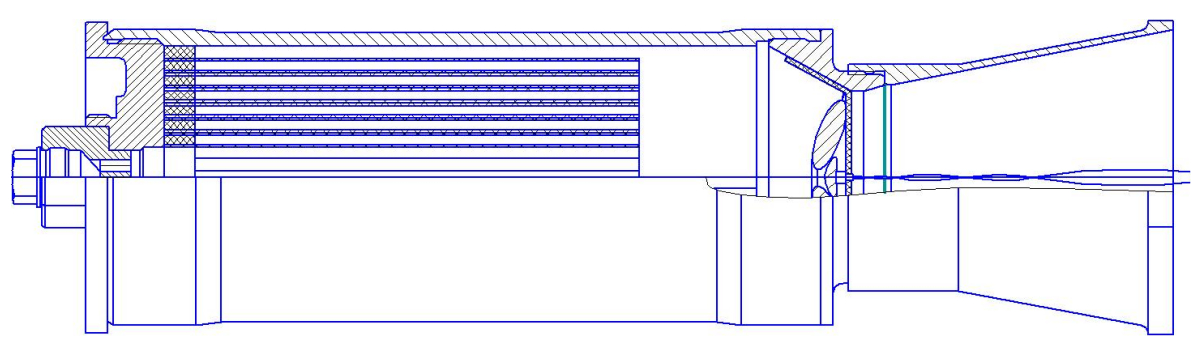

Рис. 1. Принципиальная компоновочная схема РДТТ

принципиальной компоновочной схемы такого ракетного двигателя показан на рис. 1.

Особенностью конструкции РДТТ является закрепление заряда твердого топлива на переднем днище посредством клеевой заделки непосредственно на днище или, как вариант, клеевой фиксации на штырях, также расположенных на днище.

При срабатывании ракетного двигателя в ряде случаев фиксируется частичный вылет из камеры сгорания не полностью сгоревших элементов порохового заряда (фрагментов пороховых трубок). Как следствие этого - наблюдается потеря суммарного импульса тяги, что отрицательно сказывается на выходных характеристиках РДТТ. Особенно ярко этот эффект проявляется при температуре окружающей среды $T \geq 313 \mathrm{~K}$.

В работе для оптимизации параметров РДТТ детально исследуется динамика его внутрикамерных процессов. Метод исследования постановка вычислительного эксперимента.

Рассматривается сопряженная постановка задачи, включающая в себя следующее:

- срабатывание воспламенительного устройства;

- прогрев, воспламенение и последующее нестационарное и турбулентное горение порохового заряда;

- нестационарное трехмерное ударно-волновое и вихревое гомогенно-гетерогенное течение воздуха и продуктов сгорания в камере сгорания, сопловом блоке и за сопловым блоком;

- разгерметизацию камеры сгорания и последующий вылет заглушки соплового блока.

Каждая из подзадач рассматривается во взаимосвязи и разрешается одновременно - на одном шаге по времени. При численном исследовании делается акцент на начальный этап процесса срабатывания ракетного двига- теля, поэтому выгорание свода многошашечного порохового заряда не учитывается.

Динамика процесса срабатывания воспламенительного устройства описывается на основе экспериментально-теоретического подхода, подробно изложенного в работах $[6,15]$.

Описание процесса нестационарного прогрева, воспламенения и последующего нестационарного и турбулентного горения заряда высококалорийного модифицированного баллиститного твердого топлива базируется на модели Мержанова - Дубовицкого - Соркина с учетом, в рамках подхода Горохова Липанова - Русяка, влияния газовой фазы на процесс горения в конденсированной фазе (базовые уравнения - уравнения теплопроводности и химической кинетики). Задача, дополненная замыкающими соотношениями и записанная в неравномерной (экспоненциальной) системе координат, интегрируется численно сеточным методом по явным и неявным конечно-разностным схемам. Неявные схемы разрешаются способом прогонки. Детально физико-математическая постановка задачи изложена в работах $[6,12,14-16]$.

Для описания процесса течения в камере сгорания, сопловом блоке и за сопловым блоком РДТТ применяются подходы механики сплошных многофазных сред, предложенные в работах Х.А. Рахматулина и Р.И. Нигматулина. В качестве базовой используется нестационарная система вихревых дифференциальных уравнений газовой динамики для гомогенно-гетерогенной среды (смесь газов + твердые частицы или жидкие капли), записанная в дивергентной форме. С пространственной точки зрения задача изучается в полной трехмерной постановке (без учета наличия осей, плоскостей и поверхностей симметрии). Численное интегрирование базовой системы 
уравнений, описывающей газодинамическое течение, проводится методом Ю.М. Давыдова (методом крупных частиц), хорошо себя зарекомендовавшим при решении многих нелинейных задач механики сплошных сред. В расчетах применяется явная параметрическая (три параметра), полностью консервативная конечноразностная схема метода. Используется равномерная (однородная и полностью изотропная) расчетная сетка. На нерегулярных (не совпадающих с расчетной сеткой) границах расчетной области применяется аппарат «дробных» ячеек. На непроницаемых границах расчетной области (стенке камеры сгорания, стенке соплового блока, поверхности горения заряда твердого топлива и стенке заглушки камеры сгорания) выставляются условия непротекания с учетом движения соответствующей границы. На проницаемых границах (срез соплового блока) используется экстраполяция параметров потока из расчетной области. Приход продуктов сгорания от воспламенительного устройства осуществляется в расчетные ячейки, центры масс которых расположены в потоке в зоне его установки. Приход продуктов сгорания с поверхности горения заряда твердого топлива осуществляется в расчетные ячейки, центры масс которых расположены в потоке у поверхности горения заряда твердого топлива. Более подробно физико-математическая постановка данной задачи дана в работах $[12,15,16]$.

Поступательное движение заглушки соплового блока РДТТ в виде тонкой плоской мембраны описывается уравнением движения (второй закон Ньютона). Подробно постановка этой задачи изложена в работах $[14,15]$.

Для проведения численных расчетов на ЭВМ разработан комплекс прикладных программ, включающий в себя следующие основные модули:

- модуль расчета параметров, описывающих трехмерную постановку граничных условий на криволинейной образующей области интегрирования;

- основной расчетный модуль (англ. main модуль) - расчет газодинамического течения в камере сгорания, сопловом блоке и за сопловым блоком РДТТ с учетом работы воспламенительного устройства, прогрева, воспламенения и последующего горения заряда твердого топлива и вскрытия заглушки соплового блока;

- модуль визуализации полученной расчетной информации.

Комплекс прикладных программ написан в среде программирования Kdevelop 4.6 для рабочей станции высокой производительности с операционной системой Linux Mint $17.3 \times 86-64$ на алгоритмическом языке $\mathrm{C} / \mathrm{C}++$ с использованием (для основного расчетного модуля) стандарта многопотоковой обработки информации OpenCL [17-19].

Приведем некоторые результаты численных расчетов динамики переходных внутрикамерных процессов в ракетном двигателе для мобильных комплексов с многошашечным пороховым зарядом высококалорийного модифицированного баллиститного твердого топлива. В расчетной модели, как и в условиях эксплуатации, РДТТ расположен в пусковой трубе. Все приведенные ниже параметры потока и время работы ракетного двигателя даны в безразмерном виде. На рис. 2 показано изменение во времени давления в камере сгорания РДТТ с компоновочной схемой рис. 1. Принятые обозначения: $P_{2}$ - давление вне порохового элемента в виде полой цилиндрической трубки (т.е. в камере сгорания); $P_{3}-$ давление внутри порохового элемента в виде полой цилиндрической трубки. Давление фиксируется в районе оси симметрии ( $O Z$ - ось симметрии) со стороны переднего днища. Дополнительно на рис. 3-7 дано распределение соответственно

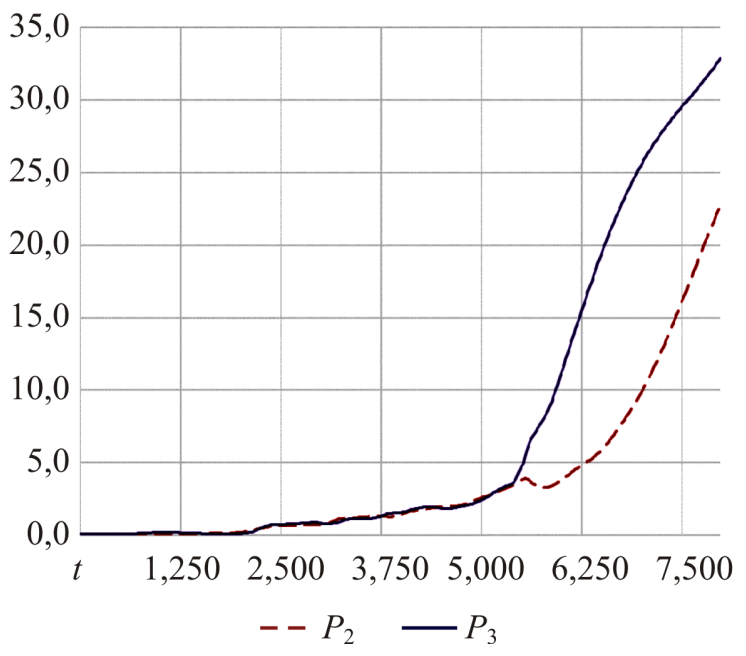

Рис. 2. Изменение во времени давления в камере сгорания исходного РДТТ 
энтропийной функции $\left(S=P / \rho^{k}\right.$, где $\rho$ плотность, $k$ - показатель адиабаты газообразных продуктов сгорания), теплоемкости при постоянном давлении $\left(c_{p}\right)$, температуры $(T)$, модуля вектора скорости $(W)$ и давления $(P)$ газообразных продуктов сгорания в данном РДТТ на момент полного вылета заглушки из соплового блока. Заглушка ракетного двигателя находится на правой границе расчетной области. На рис. 3-7 под а дано распределение параметров по сечению в плоскости $X 0 Z$. На pис. 3-7 под $\sigma-$ по сечению в плоскости $Y 0 Z$. Очевидно (см. рис. 2-7), что рассматриваемый РДТТ срабатывает аномально. Вследствие особенностей конструктивного исполнения ракетного двигателя и особенностей динамики рабочего процесса в районе переднего днища образуется существенно неоднородная как по продольному, так и по нормальному сечению к оси ракетного двигателя, плохо перемешанная, низкотемпературная газовоздушная смесь (пробка), препятствующая равномерному прогреву, зажиганию и последующему горению многошашечного порохового заряда. По этой причине внутренняя и внешняя поверхности каждого порохового элемента заряда (шашки полой цилиндрической трубки) зажигаются не одновременно и горят в различных условиях. Наблюдается эффект сегрегации (т.е. локализации или разделения) процесса горения. Перепад

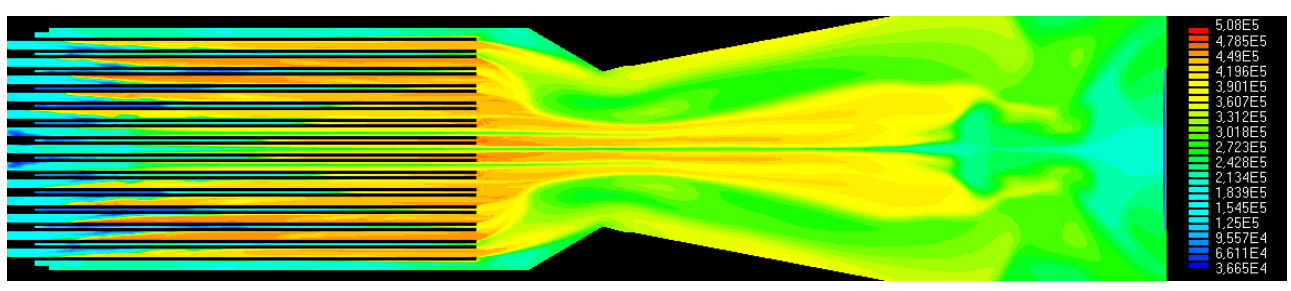

$a$

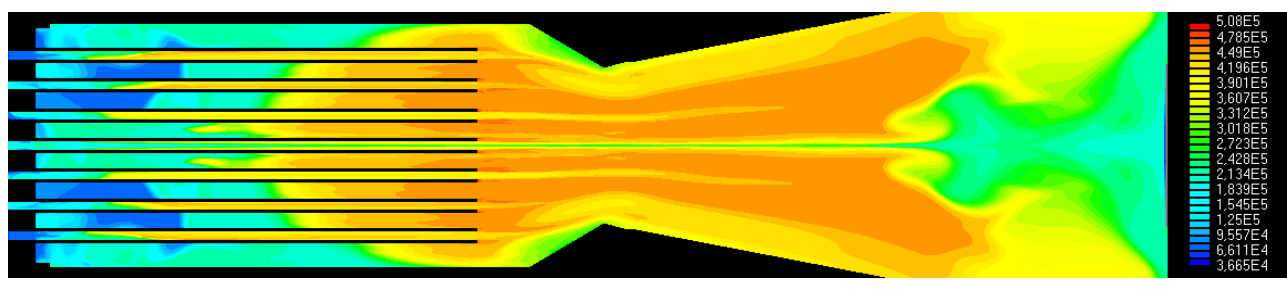

$\sigma$

Рис. 3. Распределение в РДТТ энтропийной функции газообразных продуктов сгорания в плоскостях $X 0 Z(a)$ и $Y 0 Z$ (б)

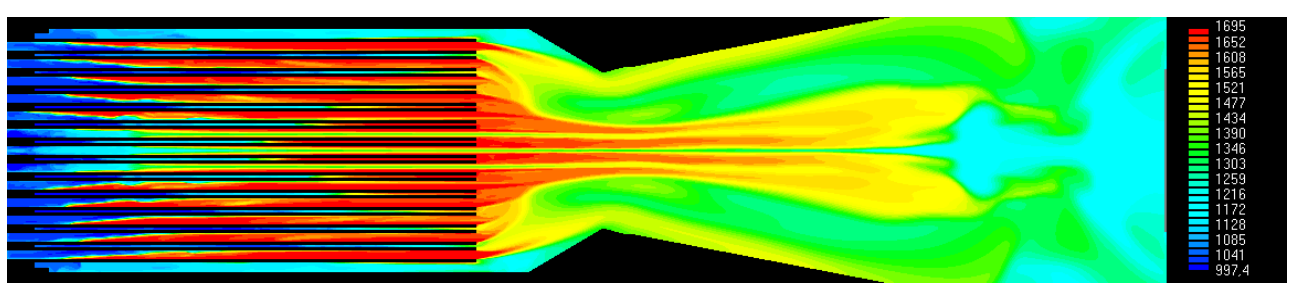

$a$

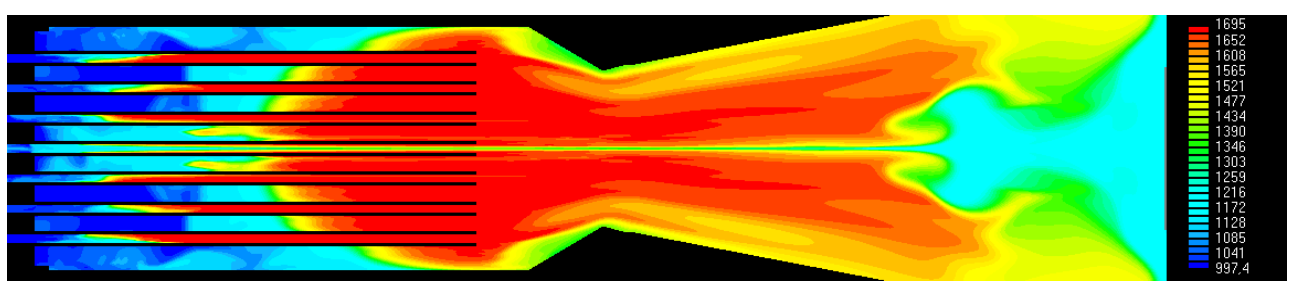

$\sigma$

Рис. 4. Распределение теплоемкости при постоянном давлении газообразных продуктов сгорания в плоскостях $X 0 Z(a)$ и $Y 0 Z$ (б) 

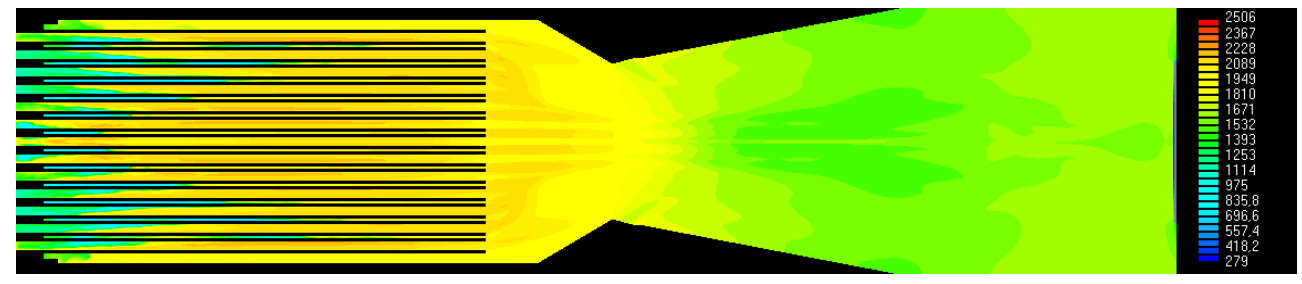

a

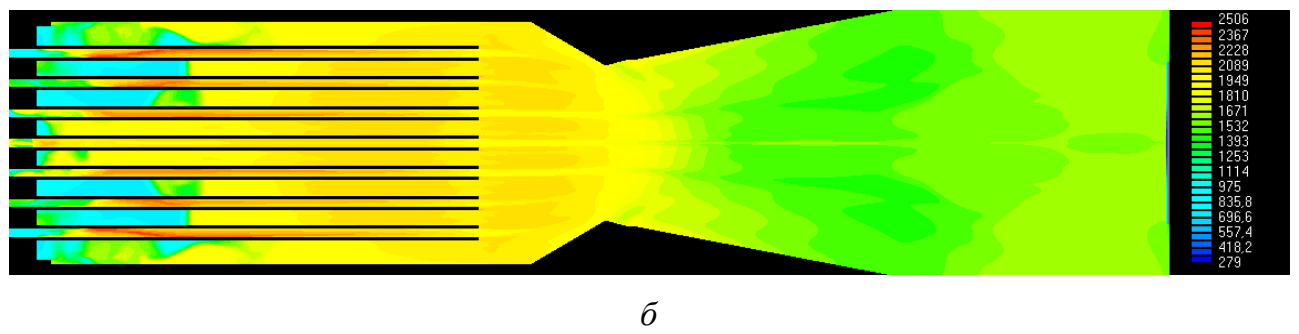

Рис. 5. Распределение температуры газообразных продуктов сгорания в плоскостях $X O Z(a)$ и $Y O Z(б)$
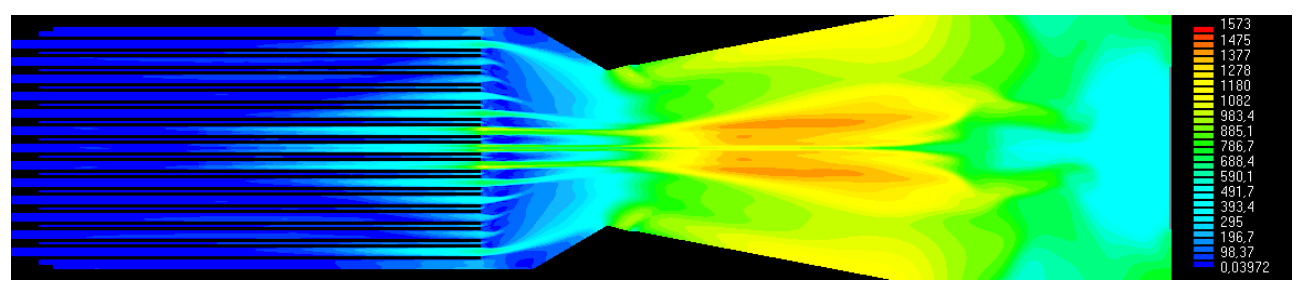

a

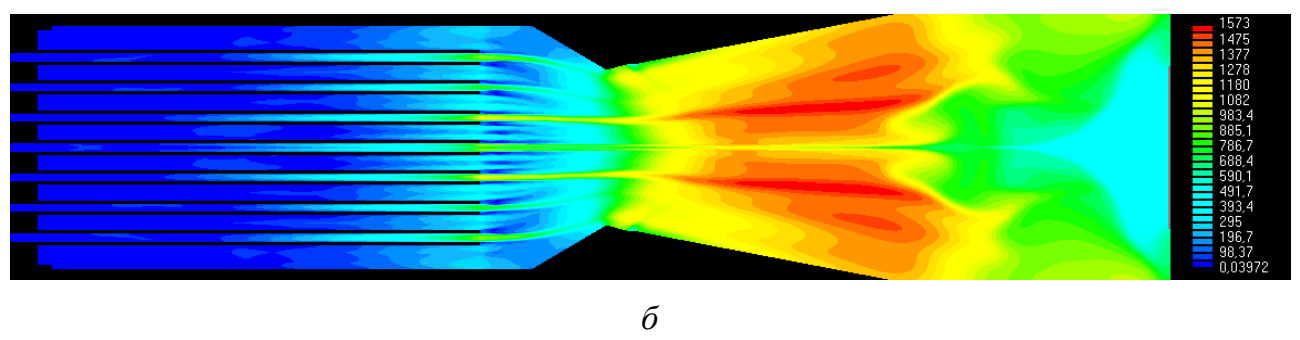

Рис. 6. Распределение модуля вектора скорости газообразных продуктов сгорания в плоскостях $X 0 Z(a)$ и $Y 0 Z$ (б)

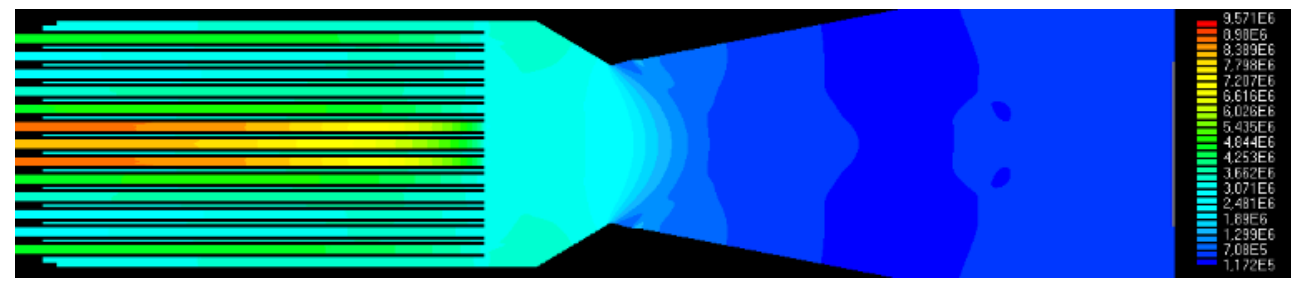

a

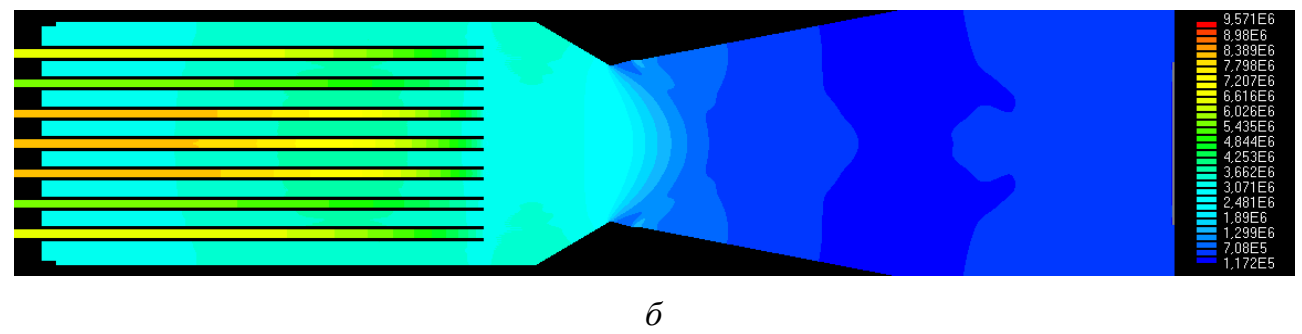

Рис. 7. Распределение давления продуктов сгорания в плоскостях $X 0 Z(a)$ и $Y 0 Z$ (б) 
давления продуктов сгорания внутри и вне пороховой трубки, особенно в приосевом пространстве камеры сгорания, может достигать нескольких десятков атмосфер (и даже более). Вследствие этого возможно разрушение пороховых элементов заряда. Кроме того, наличие клеевой заделки или, как вариант, клеевой фиксации на штырях пороховых элементов на переднем днище ракетного двигателя при значительном перепаде давления может приводить к механическому отрыву пороховых элементов и вылету их из камеры сгорания недогоревшими (глухая заделка - зона предельных напряжений и деформаций в любой конструкции). Вследствие чего тяговые и другие эксплуатационные характеристики РДТТ существенно ухудшаются.

На основании серии численных расчетов был предложен вариант компоновочной схемы ракетного двигателя, полностью исключающий эффект сегрегации процесса горения пороховых элементов заряда твердого топлива и, как следствие, существенно улучшающий режим работы РДТТ. В качестве иллюстрации этого на рис. 8 показано изменение во времени давления в ракетном двигателе с новой компоновочной схемой. Здесь давление продуктов сгорания вне

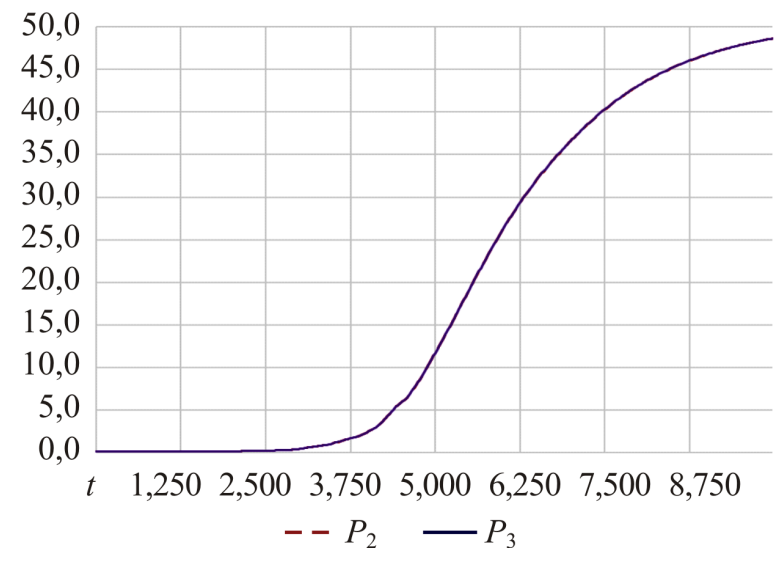

Рис. 8. Изменение во времени давления в камере сгорания РДТТ с новой компоновочной схемой

порохового элемента $P_{2}$ и внутри порохового элемента $P_{3}$ практически совпадает. Дополнительно на рис. 9 дано распределение поля давления $(P)$ в данном РДТТ на момент полного вылета заглушки из соплового блока. Заглушка ракетного двигателя находится на правой границе расчетной области. Так же, как и ранее, на рисунках под буквой $a$ дано распределение параметров по сечению в плоскости $X 0 Z$, а на рисунках под буквой $\sigma$ - по сечению в плоскости YOZ. На данную конструкцию РДТТ подана заявка на изобретение и получен патент РФ.

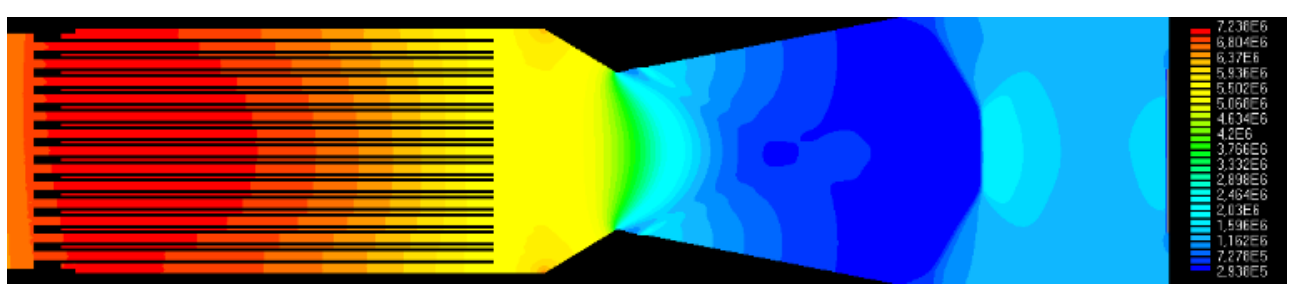

$a$

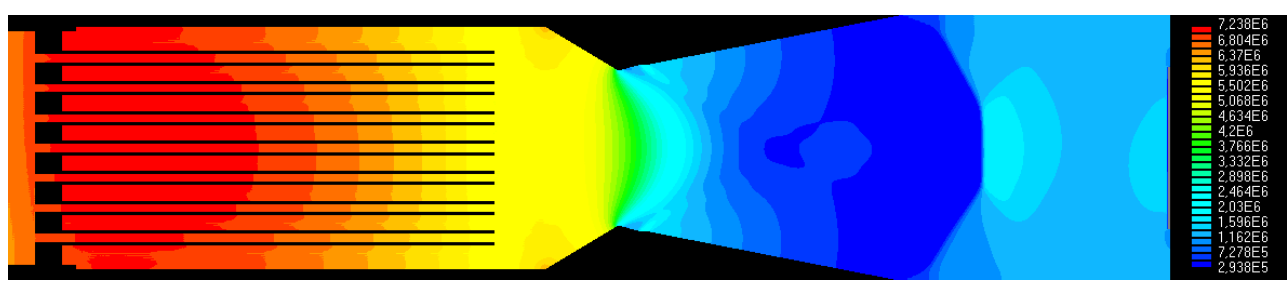

$\sigma$

Рис. 9. Распределение давления продуктов сгорания в плоскостях $X 0 Z(a)$ и $Y 0 Z$ (б) в РДТТ с новой компоновочной схемой

В заключение отметим, что полученная расчетная информация может быть успешно использована при проектировании и отработке новых образцов ракетной техники на твердом топливе с высокими энергомассовыми, проч- ностными, шумовыми и другими эксплуатационными характеристиками.

Работа выполнена при финансовой поддержке РФФИ (грант № 19-41-590006). 


\section{Библиографический список}

1. Исследование ракетных двигателей на твердом топливе / под ред. М. Саммерфилда. - М.: ИЛ, 1963. $-440 \mathrm{c}$.

2. Соркин Р.Е. Газотермодинамика ракетных двигателей на твердом топливе. - М.: Наука, 1967. - 368 с.

3. Ерохин Б.Т., Липанов А.М. Нестационарные и квазистационарные режимы работы РДТТ. М.: Машиностроение. 1977. - 200 с.

4. Алемасов В.Е., Дрегалин А.Ф., Тишин А.П. Теория ракетных двигателей. - М.: Машиностроение, 1980. -533 с.

5. Численный эксперимент в теории РДТТ / А.М. Липанов [и др.]; под ред. А.М. Липанова. - Екатеринбург: Наука, 1994. - 301 с.

6. Давыдов Ю.М., Егоров М.Ю. Численное моделирование нестационарных переходных процессов в активных и реактивных двигателях / НАПН. - М., 1999. - 272 с.

7. Внутренняя баллистика РДТТ / А.В. Алиев, Г.Н. Амарантов [и др.]; под ред. А.М. Липанова и Ю.М. Милехина; РАРАН. - М.: Машиностроение, 2007. - 504 с.

8. Твердотопливные регулируемые двигательные установки / Ю.С. Соломонов [и др.]; под ред. А.М. Липанова, Ю.С. Соломонова; РАРАН. - М.: Машиностроение, 2011. - 416 с.

9. Yamamoto M., Oguchi H. Gas-particle mixture in a spinning solid rocket motor // ISAS Report. 1983. - No. 607. - P. 1-15.

10. High performance solid rocket motor submerged nozzle/combustion cavity flowfield assessment / J.A. Freeman, J.S. Chan, J.E. Murph, K.E. Xiques // NASA Report. - 1988. - No. CR-179307. - P. 57.

11. Eulerian multi-fluid models for the simulation of dynamics and coalescence of particles in solid propellant combustion / F. Doisneau, F. Laurent, A. Murrone, J. Dupays, M. Massot // J. of Computational Physics. 2013. - Vol. 234. - P. 230-262.

12. Численное моделирование внутрикамерных процессов при выходе на режим работы ракетного двигателя твердого топлива / Г.Н. Амарантов, М.Ю. Егоров, С.М. Егоров, Д.М. Егоров, В.И. Некрасов // Вычислительная механика сплошных сред. - 2010. - Т. 3, № 3. - С. 5-17.

13. Давыдов Ю.М., Давыдова И.М., Егоров М.Ю. Неустойчивость рабочего процесса в двухкамерном ракетном двигателе на твердом топливе // Доклады академии наук. - 2011. - Т. 439, № 2. C. $188-191$.

14. Егоров М.Ю., Егоров Д.М. Численное исследование динамики внутрикамерных процессов при срабатывании бессоплового РДТТ // Известия вузов. Авиационная техника. - 2013. - № 1. - С. 51-54.

15. Численное моделирование нестационарных и нелинейных внутрикамерных процессов при срабатывании ракетного двигателя на твердом топливе специального назначения. Ч. 1. Постановка вычислительного эксперимента / М.Ю. Егоров, С.М. Егоров, Д.М. Егоров, Р.В. Мормуль // Вестник Пермского национального исследовательского политехнического университета. Аэрокосмическая техника. 2016. - № 47. - С. 53-72.

16. Егоров М.Ю., Егоров Д.М., Егоров С.М. Численное исследование динамики внутрикамерных процессов ракетного двигателя на твердом топливе особой компоновочной схемы. Ч. 1. Постановка вычислительного эксперимента // Вестник Пермского национального исследовательского политехнического университета. Аэрокосмическая техника. - 2018. - № 53. - С. 63-76.

17. Стахнов A.A. Linux. - СПб.: БХВ-Петербург, 2004. - 912 с.

18. Дерк Л. С и С++: справ. - М.: ВКК, 1997. - 592 с.

19. Programming Guide. AMD Accelerated Parallel Processing OpenCL. - Advanced Micro Devices. 2011. - URL: developer.amd.com/appsdk (available at 25 January 2020).

\section{References}

1. M. SUMMERFIELD. Issledovaniye raketnykh dvigateley na tverdom toplive [Research of rocket engines on solid fuel]. Moscow: IL, 1963, 440 p.

2. Sorkin R.E. Gazotermodinamika raketnykh dvigateley na tverdom toplive [Gas-Thermodynamics of solid-fuel rocket engines]. Moscow: Nauka, 1967, 368 p.

3. Erokhin B.T., Lipanov A.M. Nestatsionarnyye i kvazistatsionarnyye rezhimy raboty RDTT [Nonstationary and quasi-stationary modes of operation]. Moscow: Mechanical Mashinostroyeniye, 1977, $200 \mathrm{p}$.

4. Alemasov V.E., Dregalin A.F., Tishin A.P. Teoriya raketnykh dvigateley [Theory of rocket engines]. Moscow: Mashinostroyeniye, 1980, 533 p. 
5. Lipanov A.M. et al. Chislennyy eksperiment $v$ teorii RDTT [Numerical experiment in the theory of solid propellant motors]. Yekaterinburg: Nauka, 1994, $301 \mathrm{p}$.

6. Davydov Yu.M., Egorov M.Yu. Chislennoye modelirovaniye nestatsionarnykh perekhodnykh protsessov v aktivnykh i reaktivnykh dvigatelyakh [Numerical modeling of non-stationary transient processes in active and jet engines]. Moscow: NAPN, 1999, 272 p.

7. A.V. Aliyev and others. Vnutrennyaya ballistika RDTT [Internal ballistics solid propellant motors]. Ed. by A.M. Lipanov and Y.M. Milekhina. Moscow: Mashinostroyeniye, 2007, 504 p.

8. Yu.S. Solomonov et al. Tverdotoplivnyye reguliruyemyye dvigatelnyye ustanovki [Adjustable solidfuel propulsion systems]. Ed. by A.M. Lipanov, Yu.S. Solomonova. Moscow: Mashinostroyeniye, 2011, 416 p.

9. Yamamoto M., Oguchi H. Gas-particle mixture in a spinning solid rocket motor // ISAS Report No. 607, 1983, pp. 1-15.

10. Freeman J.A., Chan J.S., Murph J.E., Xiques K.E. High performance solid rocket motor submerged nozzle/combustion cavity flowfield assessment. NASA Report, 1988, No. CR-179307, 57 p.

11. Doisneau F., Laurent F., Murrone A., Dupays J., Massot M. Eulerian multi-fluid models for the simulation of dynamics and coalescence of particles in solid propellant combustion. Journal of Computational Physics, 2013, Vol. 234, pp. 230-262.

12. Amarantov G.N., Egorov M.Yu., Egorov S.M., Egorov D.M., Nekrasov V.I. Chislennoye modelirovaniye vnutrikamernykh protsessov pri vykhode na rezhim raboty raketnogo dvigatelya tvërdogo topliva [Numerical modeling of intra-chamber processes when entering the operating mode of a solid fuel rocket engine]. Computational continuum mechanics, 2010, Vol. 3, no. 3, pp. 5-17.

13. Davydov Yu.M., Davydova I.M., Egorov M.Yu. Neustoychivost rabochego protsessa v dvukhkamernom raketnom dvigatele na tverdom toplive [Instability of the working process in a two-chamber rocket engine on solid fuel]. Reports of the Russian Academy of Sciences, 2011, Vol. 439, No. 2, pp. 188-191.

14. Egorov M.Yu., Egorov D.M. Chislennoye issledovaniye dinamiki vnutrikamernykh protsessov pri srabatyvanii bessoplovogo RDTT [Numerical study of the dynamics of intra-chamber processes in the event of a popleless solid fuel rocket engine]. Russian Aeronautics, 2013, no. 1, pp. 51-54.

15. Egorov M.Yu., Egorov S.M., Egorov D.M., Mormul R.V. Chislennoye modelirovaniye nestatsionarnykh i nelineynykh vnutrikamernykh protsessov pri srabatyvanii raketnogo dvigatelya na tvërdom toplive spetsialnogo naznacheniya. Chast 1. Postanovka vychislitelnogo eksperimenta [Numerical simulation of nonstationary and nonlinear in-chamber processes when a rocket engine is fired on a special-purpose solid fuel. Part 1. Setting up a computational experiment]. PNRPU Aerospace Engineering Bulletin, 2016, no. 47, pp. 53-72.

16. Egorov M.Yu., Egorov D.M., Egorov S.M. Chislennoye issledovaniye dinamiki vnutrikamernykh protsessov raketnogo dvigatelya na tverdom toplive osoboy komponovochnoy skhemy. Chast 1. Postanovka vychislitelnogo eksperimenta [Numerical study of the dynamics of in-chamber processes of a rocket engine on solid fuel of a special layout scheme. Part 1. Statement of computational experiment]. PNRPU Engineering Aerospace Bulletin, 2018, no. 53, pp. 63-76.

17. Stahnov A.A Linux. St.Peterburg.: BKHV-Peterburg, 2004, 912 p.

18. Derk L. C and C++. Guide. Moscow: VKK, 1997, 592 p.

19. Programming Guide. AMD Accelerated Parallel Processing OpenCL. 2011. Advanced Micro Devices. [Electronic resource]. URL: developer.amd.com/appsdk (Application Date: 25/01/2020).

\section{Об авторах}

Егоров Михаил Юрьевич (Пермь, Россия) - доктор физико-математических наук, профессор, профессор кафедры «Высшая математика» ФГБОУ ВО ПНИПУ (614990, г. Пермь, Комсомольский пр., д. 29, e-mail: egorov-m-j@yandex.ru).

Городнев Виталий Олегович (Пермь, Россия) - аспирант, заместитель начальника лаборатории, АО «Научно-исследовательский институт полимерных материалов» (614113, г. Пермь, ул. Чистопольская, д. 16, e-mail: zeth@59.ru).

Егоров Дмитрий Михайлович (Пермь, Россия) - кандидат технических наук, заместитель главного конструктора, АО «Научно-исследовательский институт полимерных материалов» (614113, г. Пермь, ул. Чистопольская, д. 16, e-mail: egorovdimitriy@mail.ru).

Егоров Сергей Михайлович (Пермь, Россия) - кандидат физико-математических наук, заместитель начальника отдела, АО «Научно-исследовательский институт полимерных материалов» (614113, г. Пермь, ул. Чистопольская, д. 16, e-mail: know_nothing@bk.ru). 


\begin{abstract}
About the authors
Mikhail Yu. Egorov (Perm, Russian Federation) - Doctor of Physical and Mathematical Sciences, Professor of Higher Mathematics Department, Perm National Research Polytechnic University (29, Komsomolsky av., Perm, 614990, Russian Federation; e-mail: egorov-m-j@yandex.ru).

Vitaliy O. Gorodnev (Perm, Russian Federation) - PhD Student, Deputy Head of the Laboratory, JSC "Scientific-Research Institute of Polymer Materials" (16, Chistopolskaya st., Perm, 614113, Russian Federation; e-mail: zeth@59.ru).

Dmitry M. Egorov (Perm, Russian Federation) - CSc in Technical Sciences, Chief Designer, JSC "Scientific-Research Institute of Polymer Materials" (16, Chistopolskaya st., Perm, 614113, Russian Federation; e-mail: egorovdimitriy@mail.ru).

Sergey M. Egorov (Perm, Russian Federation) - CSc in Physical and Mathematical Sciences, Leading Researcher, JSC "Scientific-Research Institute of Polymer Materials" (16, Chistopolskaya st., Perm, 614113, Russian Federation; e-mail: know_nothing@bk.ru).
\end{abstract}

Получено 26.01.2020 